\title{
The Effect of Tympanic Membrane Perforation Site, Size and Middle Ear Volume on Hearing Loss
}

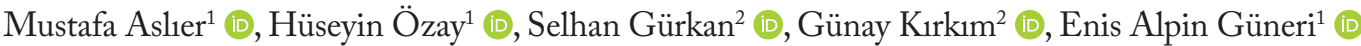 \\ Original Investigation $>{ }^{1}$ Department of Otorhinolaryngology, Dokuz Eylül University School of Medicine, İzmir, Turkey \\ ${ }^{2}$ Department of Audiology, Dokuz Eylül University School of Medicine, İzmir, Turkey
}

Abstract

ORCID IDs of the authors: M.A. 0000-0001-8257-0979; H.0̈. 0000-0001-6528-9819; S.G. 0000-0002-2872-5703; G.K. 0000-0003-4170-5317; E.A.G. 0000-0003-2592-0463.

Cite this article as: Aslier M, Özay H, Gürkan S, Krrkım G, Güneri EA. The Effect of Tympanic Membrane Perforation Site, Size and Middle

Ear Volume on Hearing Loss. Turk Arch Otorhinolaryngol 2019; 57(2): 86-90.

\section{Corresponding Author:}

Mustafa Aslıer; mustafa.aslier@deu.edu.tr

Received Date: 19.12.2018

Accepted Date: 26.04.2019

Available Online Date: 27.06.2019

DOl: 10.5152/ta0.2019.4015

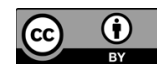

Content of this journal is licensed under a Creative Commons Attribution 4.0 International License.

Available online at www.turkarchotolaryngol.net
Objective: The aim of this study was to analyze the location and the size of perforation in cases with tympanic membrane perforation, its relation to the manubrium mallei and middle ear volume, and to investigate how these are correlated with the severity and frequencies of conductive hearing loss.

Methods: This prospectively designed study included the patients who presented to the the Department of Otorhinolaryngology at the Dokuz Eylül University with hearing loss or tinnitus complaints in the period from June 2014 through June 2017 and were identified to have tympanic membrane perforation in their otoscopic examination. Patients who underwent myringoplasty and type 1 tympanoplasty and whose airbone gap was found lower than $10 \mathrm{~dB}$ in the postoperative audiological examination were included in the study. Effects of the perforation size, the perforation site, and the relationship of the perforation with the manubrium, as well as the effects of the middle ear volume on the severity and frequency of conductive hearing loss were compared.

Results: The study included 44 ears of 38 patients (13 male and 25 female) of whom six had tympanic membrane perforation in both ears. Air conduction threshold and air-bone gap were significantly found higher if the perforation area was wide $(p<0.05)$, the perforation involved both the anterior and the posterior quadrants $(\mathrm{p}<0.05)$, had contact with the manubrium mallei $(\mathrm{p}<0.05)$, and the middle ear volume reduced $(\mathrm{p}<0.05)$.

Conclusion: Solely tympanic membrane perforation affects hearing function; nevertheless, hearing function are better in cases, which have perforations small in size, no contact with manubrium mallei and well pneumatized middle ears.

Keywords: Conductive hearing loss, tympanic membrane perforation, audiometry, tympanometry

\section{Introduction}

Tympanic membrane perforation may occur following an acute or chronic infection of the middle ear or after a trauma. Whereas the effects of perforation on the mechanism of the middle ear is complex and not fully defined, we do know that conductive hearing loss (CHL) up to $50 \mathrm{~dB}$ may occur in isolated membrane perforations with the ossicles remaining intact $(1,2)$.

The site and the size of the perforation, whether or not it contacts the manubrium mallei, as well as the volume of the middle ear and of the mastoid are some of the factors that affect the level of the hearing loss (2). Results obtained in the few previous studies show that large perforations that are posteriorly located and contact the manubrium mallei increase the CHL level, especially at lower frequencies (1-4). Likewise, severity of the hearing loss increases as the volumes of the air cells in the middle ear and the mastoid bone decrease (2). This study aimed at investigating the level to which the perforation size, location, presence of a contact between the perforation and the manubrium mallei, and middle ear and mastoid air volumes affect the severity and the frequency specificity of CHL in cases with isolated membrane perforation and with intact middle ear ossicles and inner ear functions.

\section{Methods}

The study was initiated after approval was obtained from the Ethics Committee for Non-invasive Clini- 
cal Research of the Dokuz Eylül University (approval date: 23 January 2014, protocol number: 181-SBKAEK, approval reference: 2014/02-07). Otoendoscopic images of patients who presented to the department from June 2014 through June 2017 with hearing loss or tinnitus and were observed to have tympanic membrane perforation in their otoscopic examinations were recorded, then pure tone audiometry and tympanometry tests were performed. Written consent was obtained from all patients included in the study. Otoendoscopy, pure tone audiometry and tympanometry were repeated either following their spontaneous healing or in postoperative third month in patients who showed spontaneous healing in the course of follow-up and in patients who were treated with a paper-patch technique or underwent myringoplasty or type 1 tympanoplasty. Demographic characteristics of patients such as age, gender, side with perforated membrane were recorded. Inclusion and exclusion criteria were specified to constitute a homogeneous study group of cases with isolated tympanic membrane perforation. This ensured that the study group did not include any cases with any pathologies that could affect their hearing threshold other than tympanic membrane perforation in terms of otoendoscopic, audiological or peroperative findings.

\section{Inclusion criteria}

Patients were included in the study if

1. Aged 16 years or older;

2. Showed isolated tympanic membrane perforation and normal middle ear structure in their first otoendoscopic examination;

3. Air conduction threshold was found lower than $20 \mathrm{~dB}$ at $250 \mathrm{~Hz}, 500 \mathrm{~Hz}, 1000 \mathrm{~Hz}, 2000 \mathrm{~Hz}, 4000 \mathrm{~Hz}$ frequencies and air-bone gap was found lower than $10 \mathrm{~dB}$ at $500 \mathrm{~Hz}$, $1000 \mathrm{~Hz}, 2000 \mathrm{~Hz}, 4000 \mathrm{~Hz}$ frequencies in the pure tone audiometry performed in the third month after spontaneous healing, tpe 1 tympanoplasty, myringoplasty or paper-patch application.

\section{Exclusion criteria}

Patients were excluded from the study if

1. Aged younger than 16 years;

2. Their first otoendoscopic examination

a. Showed a granulation tissue, hypoplastic mucosa, polypoid degeneration or otorrhea in the middle ear mucosa,

b. Appearance consistent with tympanosclerosis, myringosclerosis or cholesteatoma was identified;

3. Their first pure tone audiometry showed a sensorineural component that caused a hearing loss of more than $20 \mathrm{~dB}$ in bone conduction thresholds at one or more frequencies at $500 \mathrm{~Hz}, 1000 \mathrm{~Hz}, 2000 \mathrm{~Hz}, 4000 \mathrm{~Hz}$;

4. Ossicular chain damage that could affect their hearing threshold was identified in patients who had undergone tympanoplasty as part of their primary treatment ( $\mathrm{pa}^{-}$ per-patching, myringoplasty or type 1 tympanoplasty);

5. Examination in the third month after spontaneous healing or treatment (paper-patching, myringoplasty or type 1 tympanoplasty);

a. Perforation in membrane or graft material or any kind of graft failure was observed in otoendoscopic examination. b. Air conduction threshold was found higher than $20 \mathrm{~dB}$ at $250 \mathrm{~Hz}, 500 \mathrm{~Hz}, 1000 \mathrm{~Hz}, 2000 \mathrm{~Hz}, 4000 \mathrm{~Hz}$ frequencies and air-bone gap was found higher than $10 \mathrm{~dB}$ at $500 \mathrm{~Hz}, 1000 \mathrm{~Hz}, 2000 \mathrm{~Hz}, 4000 \mathrm{~Hz}$ frequencies in the pure tone audiometry;

c. Perforation, dislocation or any pathological finding that could cause functional loss was observed in the membrane or in the graft material in tympanometry test.

\section{Otoendoscopic examination}

The initial and third month otoendoscopic examinations were performed using 0 and 70-degree rigid otoendoscopy equipment (Karl Storz-Endoskope, Tuttlingen, Germany). A 70-degree endoscope was used in cases where the 0-degree endoscopic image did not reveal the entire membrane because of the external auditory canal. Photographic images were obtained using computer-aided endovision system. The site and the size of the perforation, and whether or not it contacted the manubrium mallei were analyzed on these images.

\section{Identifying the site of the perforation}

Using a technique similar to that of Mehta et al. (3), an imaginary vertical line was drawn across the manubrium mallei on the otoendoscopic images and three groups were determined:

Group 1. Perforation localized to the anterior of the line Group 2. Perforation localized to the posterior of the line Group 3. Perforation localized to both the anterior and the posterior of the line

\section{Identifying the size of the tympanic membrane perforation}

The ratio of the perforation to the entire tympanic membrane area was calculated on the images using the 'UTHSCSA Image Tool for Windows version 3.00 (University of Texas Health Science Center, San Antonio, USA). Similar to the approach used by Gaur et al. (4), four groups were defined based on the obtained data:

Group 1. Perforation involves less than $10 \%$ of the tympanic membrane area

Group 2. Perforation involves $10-20 \%$ of the tympanic membrane area

Group 3. Perforation involves $20-40 \%$ of the tympanic membrane area

Group 4. Perforation involves more than $40 \%$ of the tympanic membrane area

\section{Identifying presence of a contact between the perforation and the manubrium mallei}

The photographic images were examined to identify the relationship between the edge of the perforation and the manubrium mallei, and two groups were defined:

Group 1. The edge of perforation does not contact the manubrium mallei

Group 2. The edge of perforation contacts the manubrium mallei 


\section{Identifying the volumes of the middle ear and the mastoid bone with tympanometry}

Tympanometry was performed on all patients. The Eustachian tube was examined, and volume was not calculated in ears with an open tube. Volumes of the air gaps of the middle ear and the mastoid in patients with a blocked Eustachian tube were calculated using the method used by Mehta et al. (3). Three groups were defined based on the data obtained by this method which showed values above and below the mean value of the study group:

Group 1. Eustachian tube is open.

Group 2. Volume of air gaps of the middle ear and the mastoid bone are above the mean value

Group 3. Volume of air gaps of the middle ear and the mastoid bone are below the mean value

\section{Identifying the hearing thresholds and the air-bone gaps with pure tone audiometry}

Pure tone average 1 (PTA1) was calculated with air conduction thresholds at $500 \mathrm{~Hz}, 1000 \mathrm{~Hz}$ and $2000 \mathrm{~Hz}(0.5-2 \mathrm{kHz})$, and pure tone average 2 (PTA2) was calculated with air conduction thresholds at $1000 \mathrm{~Hz}, 2000 \mathrm{~Hz}$ and $4000 \mathrm{~Hz}(1-4 \mathrm{kHz})$.

\section{Statistical Analysis}

Inter-group differences were analyzed with the SPSS 15.0 software (SPSS; Inc., Chicago, IL, USA). The Mann-Whitney U test was used for the two-group analysis where the presence of a contact between the tympanic membrane perforation and the manubrium mallei was examined, and the Kruskal-Wallis test was used in other analyses where more than two groups were analyzed. Also the Mann-Whitney U test was used in perforation location and middle ear volume sub-group analyses. A $\mathrm{p}$-value $<0.05$ was accepted as statistically significant.

\section{Results}

The study included 44 ears of 38 patients of whom 13 were male and 25 were female. Their mean age was 35.71 years (range: $16-$ 62 years). Tympanic membrane perforation was identified in the right ear in 17 patients, in the left ear in 15 patients, and in both ears in six patients.

Evaluation of their otoendoscopic images showed perforation in the anterior quadrant in 20 ears, in the posterior quadrant in 10 ears, and both in the anterior and in the posterior quadrants in 14 ears. Perforation size was calculated less than $10 \%$ in nine ears, between 10 to $20 \%$ in 13 ears, between 20 to $40 \%$ in 11 ears, and more than $40 \%$ in in 11 ears.

Of the 44 ears in the study group, volumes could not be calculated in nine ears because their Eustachian tubes were open with a volume value greater than $7 \mathrm{ml}$. These ears were not included in the calculation so as not to affect the mean value. The mean volumes of the middle ear and the mastoid in ears with a blocked Eustachian tube was found $2.96 \mathrm{ml}$. The results in 14 ears were found greater than and the results in 21 ears were found less than the mean value.

Data on patient gender, perforation site and size, and volume of the middle ear and the mastoid, presence of contact between the perforation and the manubrium mallei are given in Table 1.

Analysis of air conduction thresholds by perforation location showed the highest mean value at $250 \mathrm{~Hz}$ before and $500 \mathrm{~Hz}$ after the spontaneous healing or treatment for all three groups. In inter-group analysis, the mean air conduction thresholds were found lowest in Group 1 and highest in Group 3 at all frequencies (p-value: $0.018,0.002,0.011,0.02$ and 0.022 , respectively at 250, 500, 1000, 2000, $4000 \mathrm{~Hz})$.

Table 1. Patient gender, perforation site and size and volume of the middle ear and the mastoid bone

\begin{tabular}{|c|c|c|}
\hline & & $\mathbf{n}$ \\
\hline \multirow[t]{2}{*}{ Gender } & Male & 13 \\
\hline & Female & 25 \\
\hline \multirow[t]{2}{*}{ Affected ear } & Right & 23 \\
\hline & Left & 21 \\
\hline \multirow[t]{3}{*}{ Location of perforation } & Group 1 Anterior perforation & 20 \\
\hline & Group 2 Posterior perforation & 10 \\
\hline & Group 3 Both anterior and posterior perforation & 14 \\
\hline \multirow[t]{4}{*}{ Size of perforation } & Group 1 Perforation involves less than $10 \%$ of the tympanic membrane area & 9 \\
\hline & Group 2 Perforation involves $10-20 \%$ of the tympanic membrane area & 13 \\
\hline & Group 3 Perforation involves $20-40 \%$ of the tympanic membrane area & 11 \\
\hline & Group 4 Perforation involves more than $40 \%$ of the tympanic membrane area & 11 \\
\hline \multirow{2}{*}{$\begin{array}{l}\text { Edge of perforation contacting } \\
\text { the manubrium mallei }\end{array}$} & Group 1 No & 24 \\
\hline & Group 2 Yes & 20 \\
\hline \multirow[t]{3}{*}{ Volume } & Group 1 Open Eustachian tube & 9 \\
\hline & Group 2 Volume of the middle ear and the mastoid bone are above average & 14 \\
\hline & Group 3 Volume of the middle ear and the mastoid bone are below average & 21 \\
\hline
\end{tabular}


Analysis of the differences in mean air-bone gap values by perforation location showed that the highest mean values were gathered at $500 \mathrm{~Hz}$ in all three location groups. In inter-group analysis, the mean air-bone gap value was found lowest in Group 1 and highest in Group 3 at all frequencies (p-values: 0.001, 0.043, $0.02,0.01$ and 0.002, respectively at 250, 500, 1000, 2000 and $4000 \mathrm{~Hz}$ ). Comparison of PTA1 and PTA2 data by perforation location also showed the lowest values in Group 1 and the highest values in Group 3 (p-values: 0.002 and 0.012 for PTA1 and PTA2, respectively).

Whereas, there were no statistically significant differences between the perforation location groups of Group 1 and Group 2 in terms of mean air conduction threshold, mean air-bone gap, and PTA1-PTA2 values on the Mann-Whitney U test (p-value: 0.248 and 0.35 for PTA1 and PTA2, respectively).

Analysis of air conduction thresholds by perforation size showed the highest mean value at $250 \mathrm{~Hz}$ before and $500 \mathrm{~Hz}$ after the spontanesous healing and/or treatment for all four groups. In inter-group analysis, the mean air conduction thresholds were found lowest in Group 1 and highest in Group 4 at all frequencies (p-value: $0.007,0.001,0.000,0,003$ and 0.004 , respectively at $250,500,1000,2000,4000 \mathrm{~Hz}$ ).

Analysis of mean air-bone gap values by perforation size for all four groups showed the highest mean values at $500 \mathrm{~Hz}$. In inter-group analysis, the mean air-bone gap value was found lowest in Group 1 and highest in Group 4 at all frequencies (p-value: $0.000,0.002,0.001$ and 0.001 , respectively at 500, 1000, 2000, $4000 \mathrm{~Hz}$ ). Comparison of PTA1 and PTA2 data by perforation size also showed the lowest values in Group 1 and the highest values in Group 4 (p-value: 0.000 and 0.001 for PTA1 and PTA2, respectively).

Analysis of the two groups defined by the presence of a contact between the perforation and the manubrium mallei, the mean values at all frequencies were identified to be statistically significantly higher in the group which there was contact ( $\mathrm{p}$-value for air conduction threshold: $0.001,0.001,0.000,0.003$ and 0.002 at 250, 500, 1000, 2000, $4000 \mathrm{~Hz}$, respectively; for air-bone gap: 0.001, $0.002,0.001$ and 0.001 at $500,1000,2000,4000 \mathrm{~Hz}$, respectively; and for PTA1 and PTA2: 0.000 and 0.000, respectively).

Analysis of the three groups defined by the volumes of the middle ear and the mastoid bone showed statistically significant differences in mean air conduction thresholds at $500 \mathrm{~Hz}$ and $1000 \mathrm{~Hz}$, air-bone gap at $500 \mathrm{~Hz}$ and $1000 \mathrm{~Hz}$ and as well as PTA1 values (p-value for air conduction threshold 0.010 and 0.037 at 500 and $1000 \mathrm{~Hz}$, respectively; for air-bone gap: 0.004 and 0.033 at 500 and $1000 \mathrm{~Hz}$, respectively; and for PTA1: 0.32). No statistically significant differences were found between the groups for the remaining parameters ( $\mathrm{p}$-value for air conduction threshold: 0.052, $0.267,0.197$ at $250,2000,4000 \mathrm{~Hz}$, respectively; for air-bone gap: 0.174 and 0.31 at 2000 and $4000 \mathrm{~Hz}$, respectively). Additionally inter-group analysis showed that the data of the group with an open Eustachian tube (Group 1) were worse than those of Group
2. Comparison between Group 2 and Group 3, excluding Group 1 , using the bivariate Mann-Whitney $U$ test showed no statistically significant differences in the mean values for air conduction threshold at $2000 \mathrm{~Hz}$ and $4000 \mathrm{~Hz}$ and for air-bone gap at 2000 $\mathrm{Hz}$ and $4000 \mathrm{~Hz}$ (p-value: 0.118, 0.089, 0.096 and 0.145 , respectively); whereas significant differences were identified among the analysis results for all remaining values ( $\mathrm{p}$-value for air conduction threshold: $0.031,0.004,0.01$ at $250,500,1000 \mathrm{~Hz}$, respectively; for air-bone gap $0.002,0.015$ at $500,1000 \mathrm{~Hz}$, respectively; for PTA 1 and PTA2: 0.012, 0.028, respectively).

\section{Discussion}

It is known that hearing loss occurs in cases with only tympanic membrane perforation and normal middle ear structures, especially at lower frequencies, and that hearing threshold increases as the frequency increases. Further, larger perforations tend to cause more severe hearing loss (1-5), because of a decrease in the physiologically vibrating area of the tympanic membrane and/or decreased proportional difference between the tympanic membrane and the base of stapes (6). Despite the limited number of previous studies in this area, the number of experimental and clinical studies remain insufficient due to the complex and difficult-to-model mechanisms of the tympanic membrane and the middle ear functions.

We excluded the patients with a middle- or inner-ear pathology from our study in order to investigate only hearing losses associated with perforation. While this approach may, in theory, create an isolated group, in practice, it cannot eliminate the probability of various pathologies that might have had an impact on the hearing loss. Per our methodology, we excluded the patients that showed any additional finding indicative of a middle- or inner-ear disease in the examination and in audiological tests and included only those who had a successfully healed graft and fully recovered hearing.

Studies examining the effects of the perforation location on hearing thresholds report that perforations localized to the posterior quadrant eliminate phase difference discrimination and raise hearing thresholds $(1,7,8)$. Nevertheless, possible changes in functional hearing frequencies $(4000 \mathrm{~Hz}$ and lower) have not been sufficiently examined in these studies. In fact, more recent experimental and clinical studies report that phase differences affect the inner ear at the same level in perforations localized to the anterior and posterior quadrants $(1,3)$. In our study, we first created three groups to review our results and found statistically significant differences. After the initial analysis we excluded the group with perforations involving both the anterior and the posterior quadrants since the size of such perforations would be larger and analyzed the remaining two groups and found no statistically significant differences between the perforations 1ocalized to the anterior quadrant and the posterior quadrant.

The effects of the size of the perforation on hearing thresholds is a relatively simpler subject. As expected, thresholds tend to decrease, and hearing worsens as the size of perforation increases. Despite the differences in method, many studies report comparable results $(1-3,6,9)$. Some studies have calculated, hence as- 
sessed the perforation area quantitatively $(1,3)$. This approach is a challenging one that required calibration and standardization. Another study reported in the literature conducted their analysis individually on the four quadrants of the tympanic membrane based on the number of quadrants involved by the perforation (5). In our study, we used the percentile ratio value as also used by Park et al. (2) and Gaur et al. (4) as this is a semi-quantitative and simpler technique. In this technique, the percentile ratio of the area of the tympanic membrane perforation obtained in otoendoscopic records to the total area of the membrane is calculated. As mentioned, although different techniques were used in different studies, the results of these studies show that the severity of hearing loss increases as the perforation size increases $(2-5)$. In our study, too, hearing loss was most severe in the group with the largest perforation size among the groups.

Tympanic membrane perforations that contact the manubrium mallei can be named as malleolar and those that do not contact can be named as non-malleolar. More severe hearing losses have been shown in malleolar perforations $(5,6,10)$. In our study, we, too, identified higher hearing thresholds in cases with malleolar perforations.

According to the results obtained in tympanomastoidectomy studies, a minimum of $0.5 \mathrm{ml}$ air space volume is needed in the middle ear in order to ensure optimum sound transmission (11). The amount of air in the middle ear affects sound transmission, however, different techniques are reported to have been used in the calculation of this volume. While some studies calculated this volume using computed tomography, some have simply analyzed the values obtained in tympanometry. In their respective studies where Park et al. (2) used computed tomography and Mehta et al. (3) used tympanometry, both groups of authors report that air-bone gap averages decreased as the middle ear and mastoid bone air cell volumes increased. In our study, we obtained the best hearing level results in ears with larger volumes. While this difference was not significant at high frequencies, it was statistically significant at $1000 \mathrm{~Hz}$ and lower frequencies. Hearing thresholds were identified to be higher in groups with open Eustachian tube and low volume.

While it has been reported that the conductive hearing loss increases as size of the perforation increases and does not vary by the other factors such as; location of the perforation (3); there are clinical studies that showed different gains on acoustic transmission and hearing results between different type of type 1 tympanoplasty surgeries $(12,13)$. Therefore, physical examination to define preoperative characteristics of the tympanic membrane perforation is crucial to plan the optimal surgery and to have an idea about functional results after the surgery.

\section{Conclusion}

To briefly evaluate all of the results we obtained in our study: hearing threshold, hence hearing loss increases in patients with an isolated tympanic membrane perforation if their middle ear volume is reduced and a large size perforation contacts the manubrium mallei.
Ethics Committee Approval: Ethics committee approval was received for this study from the Ethics Committee for Non-invasive Clinical Research of the Dokuz Eylül University (Approval Date: 23 January 2014, Approval Reference: 2014/02-07).

Informed Consent: Written informed consent was obtained from patients who participated in this study.

Peer-review: Externally peer-reviewed.

Author Contributions: Concept - M.A., E.A.G.; Design - M.A., H.Ö., E.A.G.; Supervision - E.A.G., G.K.; Resource - M.A., H.Ö., E.A.G.; Materials - H.Ö., M.A., S.G.; Data Collection and/or Processing - M.A., H.Ö., S.G.; Analysis and/or Interpretation - M.A., G.K., S.G.; Literature Search - M.A., E.A.G.; Writing - M.A., H.Ö.; Critical Reviews - M.A., E.A.G., G.K.

Conflict of Interest: The authors have no conflicts of interest to declare.

Financial Disclosure: This study was supported by a grant from Dokuz Eylül University Research Foundation.

\section{References}

1. Voss SE, Rosowski JJ, Merchant SN, Peake WT. How do tympanic-membrane perforations affect human middle-ear sound transmission? Acta Otolaryngol 2001; 121; 169-73. [CrossRef]

2. Park H, Hong SN, Kim HS, Han JJ, Chung J, Suh MW, et al. Determinants of conductive hearing loss in tympanic membrane perforation. Clin Exp Otorhinolaryngol 2015; 8; 92-6. [CrossRef]

3. Mehta RP, Rosowski JJ, Voss SE, O'Neil E, Merchant SN. Determinants of hearing loss in perforations of the tympanic membrane. Otol Neurotol 2006; 27; 136-43. [CrossRef]

4. Gaur S, Sinha ON, Bhushan A, Batni G. Observations on tympanic membrane perforations (safe type) and hearing loss. Indian J Otolaryngol Head Neck Surg 2017; 69; 29-34. [CrossRef]

5. Pannu KK, Chadha S, Kumar D, Preeti. Evaluation of hearing loss in tympanic membrane perforation. Indian J Otolaryngol Head Neck Surg 2011; 63; 208-13. [CrossRef]

6. Ahmad SW, Ramani GV. Hearing loss in perforations of the tympanic membrane. J Laryngol Otol 1979; 93: 1091-8. [CrossRef]

7. Voss SE, Rosowski JJ, Merchant SN, Peake WT. Middle-ear function with tympanic-membrane perforations: I. Measurements and mechanisms. J Acoust Soc Am 2001; 110; 1432-44. [CrossRef]

8. Voss SE, Rosowski JJ, Merchant SN, Peake WT. Middle-ear function with tympanic-membrane perforations: II. A simple model. J Acoust Soc Am 2001; 110: 1445-52. [CrossRef]

9. Gulati SP, Sachdeva OP, Kumar P, Sachdeva A Audiological profile in CSOM. Indian J Otolaryngol 2002; 8; 24-8.

10. Shah S, Bhat V, Gupta D, Sinha V. A study of correlation of site and size of perforation with deafness. Indian J Otology 2006; 12: 46-9.

11. Rosowski JJ, Merchant SN. Mechanical and acoustic analysis of middle ear reconstruction. Am J Otol 1995; 16: 486-97.

12. Yüksel Aslıer NG, Gürkan S, Aslıer M, Kirkim G, Güneri EA, Ikiz AÖ. Sound energy absorbance characteristics of cartilage grafts used in type 1 tympanoplasty. Auris Nasus Larynx 2018; 45: 985-93. [CrossRef]

13. Jalali MM, Motasaddi M, Kouhi A, Dabiri S, Soleimani R. Comparison of cartilage with temporalis fascia tympanoplasty: A meta-analysis of comparative studies. Laryngoscope 2017; 127: 213948. [CrossRef] 